\title{
Association between reduced quality of life and depression in patients with type 2 diabetes mellitus: a cohort study in a Mexican population
}

This article was published in the following Dove Press journal: Neuropsychiatric Disease and Treatment

Isela Esther Juárez-Rojop,' Carlos Mario FortunyFalconi, ${ }^{2}$ Thelma Beatriz González-Castro, ${ }^{3}$ Carlos Alfonso Tovilla-Zárate, ${ }^{2}$ Mario Villar-Soto, ${ }^{4}$ Ester Rodríguez Sanchez, ${ }^{4}$ Yazmín Hernández-Díaz, ${ }^{3}$ María Lilia López-Narvaez, ${ }^{5}$ Jorge L Ble-Castillo,' Nonanzit Pérez-Hernández, ${ }^{6}$ José Manuel Rodríguez-Pérez

'Multidisciplinary Academic Division of Health Sciences, Juarez Autonomous University of Tabasco, Villahermosa, Tabasco, Mexico; ${ }^{2}$ Multidisciplinary Academic Division of Comalcalco, Juarez Autonomous University of Tabasco, Comalcalco, Tabasco, Mexico; ${ }^{3}$ Multidisciplinary Academic Division of Jalpa de Méndez, Juarez Autonomous University of Tabasco, Jalpa de Méndez, Tabasco, Mexico; ${ }^{4}$ Psychiatric Care Services, Hospital of high specialty "Gustavo A. Rovirosa Pérez", Ministry of Health, Villahermosa, Tabasco, Mexico; ${ }^{5}$ Pediatric Care Services, General Hospital of Yajalon "Dr. Manuel Velasco Suarez", Yajalon, Chiapas, Mexico; ${ }^{6}$ Department of Molecular Biology, National Institute of Cardiology Ignacio Chávez, Mexico City, Mexico

Correspondence: Carlos Alfonso Tovilla-Zárate

División Académica Multidisciplinaria de Comalcalco, Universidad Juárez Autónoma de Tabasco, Ranchería Sur, Cuarta Sección, CP 86650, Comalcalco, Tabasco, México

Email alfonso_tovillaz@yahoo.com.mx
Background: Diabetes mellitus is a chronic disease that requires attention and commitment on the part of patients; improving the quality of life of these patients reduces health costs, morbidity, and mortality. We focused on investigating the factors related with the quality of life and depression symptomatology in patients with type 2 diabetes.

Participants and methods: A total of 173 Mexican patients with type 2 diabetes were recruited. An interview face-to-face, a sociodemographic characteristics questionnaire, the Short Form 36 (SF-36), and the Clinical Epidemiological Studies of Depression were applied. The biochemical parameters measured were blood glucose, cholesterol, triacylglycerol levels, and glycated hemoglobin.

Results: In all SF-36 subscales, female patients had lower scores in comparison with male patients; individuals $\geq 65$ years of age showed less physical function. We observed that married patients presented a better quality of life than people who were widowed or divorced $(P<0.05)$. Those with high rates of lipids showed decreased scores all the subscales of SF-36. Finally, we observed that depression was the major factor that decreased quality of life in patients with diabetes.

Conclusion: Our results suggest that untreated and unrecognized depression can decrease the quality of life in patients with diabetes mellitus type 2. Therefore, health care professionals need to consider these findings when treating patients with diabetes. Due to the limited number of patients included in the present study, more studies are needed, studying larger samples in order to provide conclusive results.

Keywords: diabetes, depression, quality of life, Mexican population

\section{Introduction}

According to the International Diabetes Federation, in 2015, 415 million people suffer diabetes, and it has become one of the greatest health emergencies of the 21 st century. ${ }^{1}$ Type 2 diabetes mellitus (T2DM) is a chronic disease with significant implications on global society and economy that requires attention and commitment on the part of patients in order to reduce comorbidities. ${ }^{2,3}$ North America and the Caribbean have the highest prevalence of individuals with diabetes in comparison with other regions. For instance, Mexico ranks sixth for diabetes worldwide, with 11.5 million diabetic people and a prevalence of $9.4 \%$ in $2016 .^{2}$

T2DM has detrimental effects on health outcomes including quality of life. The quality of life of these patient is intimately linked to the level of education of the patient, along with the idea that he/she has about the management of diabetes mellitus as well as the comorbidities that can result from it. ${ }^{4,5}$ Diabetes mellitus itself decreases the 
patient's quality of life, but along with other comorbidities, gradually affects the overall health, including the mental health of the patients who develop psychiatric comorbidities such as depression and anxiety. ${ }^{6,7}$

Depression is one of the most common comorbidities among patients with diabetes; several studies suggest that $30 \%$ of individuals with diabetes mellitus show depressive symptomatology, and almost $10 \%$ suffer major depression. ${ }^{8-10}$ Diabetes with depression cause increased health care costs, because patients tend to have more diabetes-related complications, which also lead to greater dysfunction and a worse quality of life. ${ }^{1-13}$ Therefore, we conducted a populationbased study targeting T2DM patients in a Mexican population. The objectives of this present study were to determine the quality of life and presence of depression in individuals with T2DM and to assess the relationship between quality of life and depression in Mexican patients with T2DM.

\section{Participants and methods Participants}

Potential participants were identified at the Clinic of Diabetes of the third-level hospital "High Especially Regional Hospital Dr Gustavo A Rovirosa Perez" in Villahermosa city, Tabasco state, in southeastern Mexico. The participants were enrolled from January 2017 to June 2017. All individuals that were diagnosed with T2DM were invited to participate in the study.

We invited all the patients who attended the diabetes clinic. The individuals who accepted to participate in this study were included in compliance with the commission of ethics. It is important to mention that the patients' decision to participate in the present study did not affect their status at the "Rovirosa" Hospital. The participation was voluntary; patients who wanted to participate were given an explanation of all the objectives of the research, and then all of them signed a written informed consent. They did not receive any economical remuneration. It is important to highlight that the study was approved by the local ethics committee of the "Rovirosa" Hospital (00228/16); the study followed all the objectives remarked on in the ethical standards convened in the 1964 Declaration of Helsinki.

The inclusion criteria were as follows: individuals had to be between 18 and 87 years of age, had to be diagnosed with T2DM, had to be in treatment at the diabetes clinic for a duration of at least 1 year, and had to have received at least two lessons on diabetes education. The exclusion criteria were patients who had been diagnosed with concomitant neurological illness and/or major depression, and patients who showed clinical parameters of Maturity Onset Diabetes of the Young.

\section{Clinical measures}

First, all the patients answered a semi-structured standard questionnaire to evaluate their sociodemographic characteristics. Then, a physician interviewed each patient, collecting information about their pharmacotherapy, habits, if they consumed any drugs, and if they presented diabetes complications and comorbidities. Weight and height were measured to calculate the body mass index according to the guidelines of the International Obesity Taskforce. ${ }^{14}$

\section{Fatty liver, neuropathy, and nephropathy evaluations}

All patients were evaluated with diapason and monofilament test to observe the presence of neuropathy. Nephropathy was diagnosed following the Mexican official norm NOM-015, 15,16 which indicates that in patients with diabetes and risk factor for renal chronic disease it is necessary to measure serum creatinine and to quantify the glomerular filtration rate (GFR). The GFR was quantified based on the modification of diet in renal disease. Finally, fatty liver was evaluated by ultrasonography using the Clear Value Scale.

\section{Depression diagnoses and evaluation}

We measured depression using the Clinical Epidemiological Studies of Depression in Spanish. ${ }^{17}$ In the Mexican population, the reported Cronbach $\alpha$ score is $0.90 .{ }^{17}$ This questionnaire consists of 35 items ordered from 1 to 35 ; those items measure symptoms defined by the American Psychiatric Association Diagnostic and Statistical Manual of Mental Disorders, fourth edition $(D S M-I V) .{ }^{18}$ Also, a psychiatrist diagnosed depression following the DSM-5. ${ }^{19}$

\section{Quality of life measure}

To rate the quality of life of each patient, we used the Short Form-36 (SF-36) of the standardized questionnaire health survey validated in Mexico. ${ }^{20}$ The SF-36 consists of eight subscales, physical function, role limitation due to physical health, role limitation due to emotional problems, energy/ fatigue, emotional well-being, social function, pain, and general health; at the same time, those subscales include 36 items which evaluate the quality of life.

Biochemical parameters: Biochemical parameters including blood glucose, cholesterol, and triacylglycerol levels were analyzed in fasting conditions using a Clinical Chemistry System ERBA XL200-Mannheim (Erba Mannheim, Mannheim, Germany). Glycated hemoglobin (HbA1c) and total hemoglobin $(\mathrm{tHb})$ concentrations were determined by colorimetric method. 


\section{Statistical analysis}

Demographic and clinical characteristic were expressed as frequencies and percentages for categorical variables. For continuous variables we used mean and SD. The Kolmogorov-Smirnov test was used to analyze whether our data were under normal distribution. The KolmogorovSmirnov test showed a normal distribution of the SF-36 scores, with $P$-values $>0.05$. Then, we were able to use the Student's $t$-test. The statistical software package SPSS version 22.0 (IBM Corporation, Armonk, NY, USA) for Windows $\mathrm{PC}$ was used for the data analyses, and significance levels were set as $P \leq 0.05$.

The statistical power was calculated using the program G*Power 3.1.9.2 (Heinrich-Heine-Universität Düsseldorf, Düsseldorf, Germany) for a post hoc analysis to detect the medium effect size according to Cohen's definitions $(d=0.5)$; with a total sample size of 173 the statistical power was of 0.99 .

\section{Results}

\section{Clinical characteristics}

We initially recruited 200 individuals with diabetes mellitus; however, only 173 completed all the requirements of the study. The majority of patients included were females $(\mathrm{n}=125 ; 72.3 \%)$. The mean age was 55 years old. The prevalence of obesity was $47.12 \%$ (95\% CI: $39.42-54.83$ ). The prevalence of overweight and obesity was $82.75 \%(95 \% \mathrm{CI}$ : 76.85-88.66) (Table 1). The majority of patients had $<6$ years of schooling and a low socioeconomic level. The sociodemographic characteristics are shown in Table 1.

We observed that most patients had been diagnosed with diabetes for 11-19 years. It is important to highlight that almost all of them had HbA1c higher than normal (68.8\% 95 CI: 61.19-75.58). Also, many of them used insulin (75.7\%) and were even undergoing hypoglycemic therapies (93.1\%) and even antihypertensive treatment (59.5\%). Additionally, we observed that 33 patients had depression $(19.07 \%$ CI: 12.93-25.21). More characteristics of the patients are shown in Table 2.

\section{Sociodemographic characteristic and quality of life}

To evaluate the quality of life, we used the SF-36 health survey and the sociodemographic characteristics. We could see differences by gender: males had better results than females in "role limitation due to emotional problems" and "emotional well-being" subscales from the SF-36. For the age comparison, we observed that people $\geq 65$ years of age had decreased physical function $(P=0.005)$ and suffered
Table I Sociodemographic characteristics of the studied population

\begin{tabular}{l|l|l}
\hline Sociodemographic characteristics & $\mathbf{n}=\mathbf{I 7 3}$ & Percentage \\
\hline Gender & & \\
$\quad$ Female & 125 & 72.3 \\
$\quad$ Male & 48 & 27.7 \\
Age (years) & 10 & \\
$\quad<29$ & 127 & 5.8 \\
$30-65$ & 36 & 73.4 \\
$>65$ & $55.06 \pm \mid 3.72$ & 20.8 \\
Age mean \pm SD (minimum-maximum) & & \\
Body mass index $\left(\mathrm{kg} / \mathrm{m}^{2}\right)$ & 29 & \\
Normal & 62 & 16.8 \\
Overweight & 82 & 35.8 \\
Obese & & 47.4 \\
Marital status & 108 & \\
$\quad$ Married & 30 & 62.4 \\
Single & 18 & 17.3 \\
Widowed & 17 & 10.4 \\
Divorced & & 9.8 \\
Education & 98 & \\
Up to 6 years & 75 & 56.6 \\
More than 6 years & & 43.4 \\
Socioeconomic level & 50 & \\
Medium & 123 & 28.9 \\
Low & 24 & 71.1 \\
Occupation & 84 & 13.9 \\
Does not work & 53 & 48.6 \\
Housewife & 27 & 2.9 \\
Student & & 19.1 \\
Part-time job & & 15.5 \\
Full-time job & & \\
\hline
\end{tabular}

more pain $(P=0.012)$. In the analysis of body mass index, there were no significant differences for the parameters measured. Regarding the widowed and divorced population, we observed a digression in all the subscales of SF-36 $(P<0.05)$ except in their emotional well-being. For their occupation, we observed that the ones who did not work had lower scores in the "physical function" subscale $(P<0.001)$ as well as in the "pain" subscale $(P=0.004)$ (Table 3$)$.

\section{Clinical characteristics and quality of life}

In the quality of life comparison, we noticed that patients who had high levels of triglycerides also had low income, and their general health was also poor according to the scores obtained on the subscales of SF-36. In fact, having high levels of cholesterol affected their physical function, caused role limitations, led to energy-fatigue, and decreased their general health (Table 4).

\section{Depression and quality of life}

Finally, we analyzed the role of depression and the quality of life in patients with diabetes mellitus. We found differences 
Table 2 Clinical characteristics of diabetic patients included in the present study

\begin{tabular}{|c|c|c|}
\hline Diabetes features & $n=173$ & Percentage \\
\hline \multicolumn{3}{|l|}{ Diagnosis of diabetes } \\
\hline $1-10$ years & 55 & 31.8 \\
\hline $11-19$ years & 65 & 37.6 \\
\hline 20 and $\uparrow$ & 53 & 30.6 \\
\hline \multicolumn{3}{|l|}{$\mathrm{Hblac}(\%)$} \\
\hline $7.5 \downarrow$ & 54 & 31.2 \\
\hline 7.5 and $\uparrow$ & 119 & 68.8 \\
\hline Mean \pm SD (minimum-maximum) & $8.8 \mathrm{I} \pm 2.44$ & $(5.40-21.10)$ \\
\hline \multicolumn{3}{|l|}{ Drug use } \\
\hline \multicolumn{3}{|l|}{ Insulin } \\
\hline Yes & $|3|$ & 75.7 \\
\hline No & 42 & 24.3 \\
\hline \multicolumn{3}{|l|}{ Hypoglycemic therapy } \\
\hline Yes & 161 & 93.1 \\
\hline No & 12 & 6.9 \\
\hline \multicolumn{3}{|l|}{ Antihypertensive } \\
\hline Yes & 103 & 59.5 \\
\hline No & 70 & 40.5 \\
\hline \multicolumn{3}{|l|}{ Heart disease } \\
\hline Yes & 99 & 57.2 \\
\hline No & 74 & 42.8 \\
\hline \multicolumn{3}{|l|}{ Cerebral vascular event } \\
\hline Yes & 12 & 6.9 \\
\hline No & 161 & 93.1 \\
\hline \multicolumn{3}{|l|}{ Hyperlipidemia } \\
\hline Yes & 114 & 65.9 \\
\hline No & 59 & 34.1 \\
\hline \multicolumn{3}{|l|}{ Liver disease } \\
\hline Yes & 25 & 14.5 \\
\hline No & 148 & 85.5 \\
\hline \multicolumn{3}{|l|}{ Neuropathy } \\
\hline Yes & 55 & 31.8 \\
\hline No & 118 & 68.2 \\
\hline \multicolumn{3}{|l|}{ Nephropathy } \\
\hline Yes & 42 & 24.3 \\
\hline No & $|3|$ & 75.7 \\
\hline \multicolumn{3}{|l|}{ Depression } \\
\hline Yes & 33 & 19.1 \\
\hline No & 140 & 80.9 \\
\hline
\end{tabular}

between patients with and without depression in all the subscales of SF-36 (Table 5). Patients with depression showed a decrease in all the subscales: lower quality of life, role limitation due to physical health, role limitation due to emotional problems, energy/fatigue, and emotional wellbeing $(P<0.001)$. When we considered physical and mental components together, we observed statistical differences between depressive and nondepressive patients.

\section{Discussion}

In the present study, we determined the quality of life of patients with diabetes in relation to their sociodemographic characteristics; we also compared their quality of life in the presence of depression. To the best of our knowledge, this is the first study that has measured the consequences of having T2DM along with untreated depression on the quality of life of these patients in a Mexican population.

According to the International Diabetes Federation, the majority of individuals with T2DM are living in developing countries such as Mexico. ${ }^{1}$ Tence, the relevance of studying the relationship between quality of life-Depression and Type 2 diabetes in our population. In order to get a better comprehension of factors that could influence over the quality of life of patients with T2DM, we addressed the role of concomitant depression. We observed that diabetic patients with undiagnosed and untreated depression showed a decreased quality of life. Furthermore, these patients showed lower scores in all the subscales of quality of life, which is in agreement with previous studies. ${ }^{7,21-23}$ It is well known that people with degenerative chronic diseases, such as diabetes, are more susceptible to develop depression. ${ }^{24}$ Patients with diabetes have twice the risk to developing depression than patients without it. ${ }^{25}$ Furthermore, it has been suggested that people with depression are more likely to eat foods rich in saturated fats and avoid fruits and vegetables, which may contribute to an increased risk of having uncontrolled diabetes or a high risk of developing it. ${ }^{26,27}$

There are some explanations of the biological mechanism associated with depression and T2DM. First, an increase of ACTH levels could be due to an enhanced activity of hypothalamic-pituitary-adrenal axis; hypothalamic-pituitaryadrenal axis itself could impair glucose metabolism. ${ }^{28}$ Second, the presence of chronic inflammation leads to inflammatory markers, such as c-reactive protein and TNF- $\alpha$, and proinflammatory cytokines that are increased in diabetes mellitus. ${ }^{10,29}$ Those biological mechanisms cause comorbidities such as depression, and it is probable that these together decrease the quality of life of these patients.

We also observed that the marital status was a factor that modified scores on all the subscales of SF-36. Previous reports have also shown that being married is a protective factor against low quality of life. ${ }^{30}$ In consequence, it is necessary to pay more attention to patients who live alone, are widowed, or are divorced. ${ }^{31}$

Regarding the clinical variables, we observed that higher cholesterol levels were the principal factor for a decreased quality of life in our Mexican patients, affecting particularly the physical function and emotional well-being scores. In this sense, previous reports have shown that patients with high cholesterol levels in combination with impaired glucose had lower outcomes in the physical component and mental 


\begin{tabular}{|c|c|c|c|c|c|c|c|}
\hline 施 & 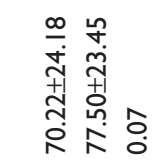 & 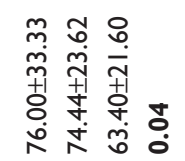 & 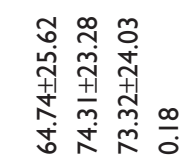 & 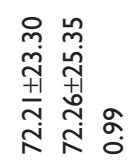 & 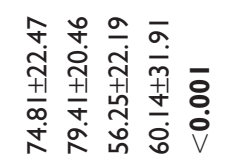 & 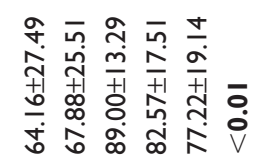 & 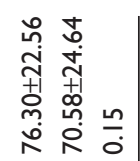 \\
\hline 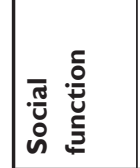 & 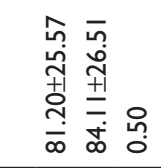 & 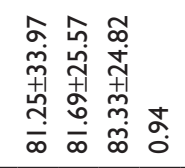 & 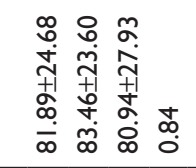 & 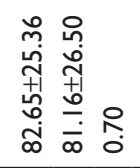 & 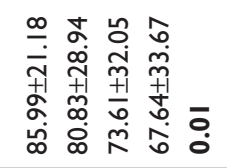 & 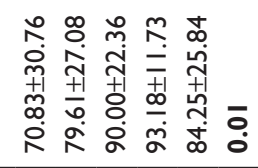 & 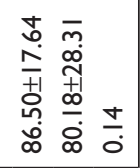 \\
\hline 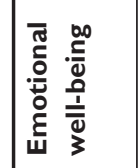 & 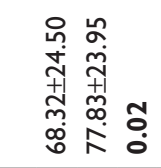 & 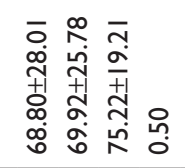 & 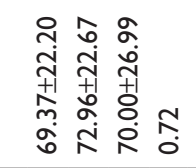 & 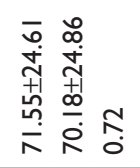 & 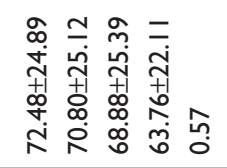 & 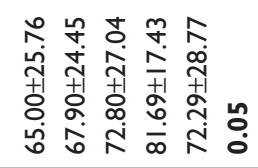 & 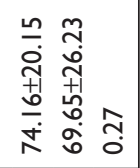 \\
\hline 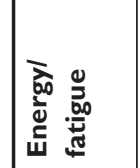 & 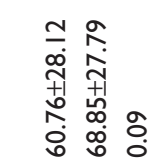 & 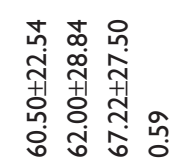 & 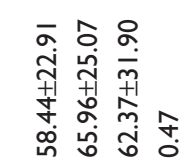 & 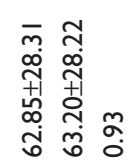 & 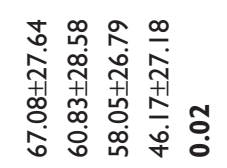 & 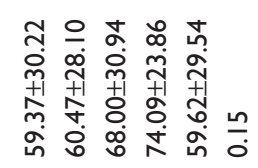 & 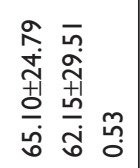 \\
\hline 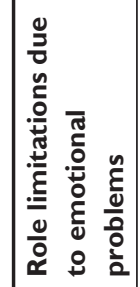 & 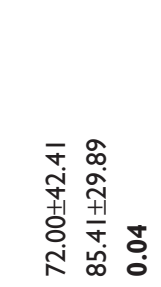 & 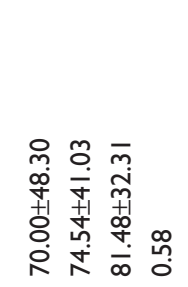 & 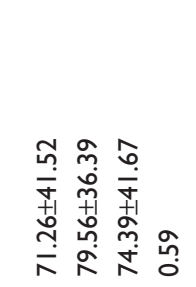 & 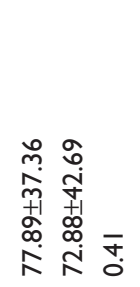 & 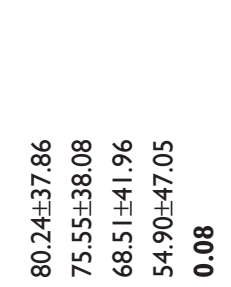 & 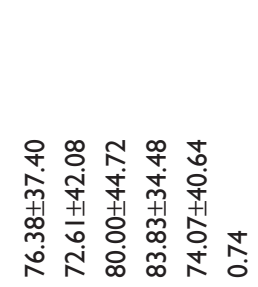 & 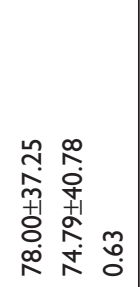 \\
\hline 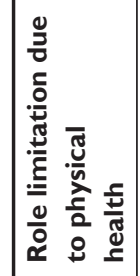 & 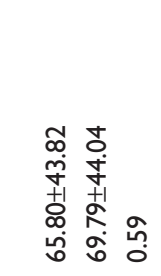 & 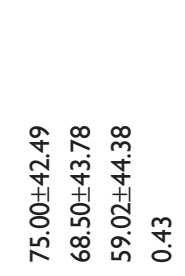 & 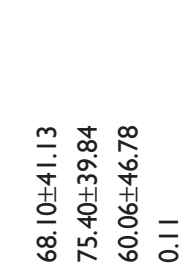 & 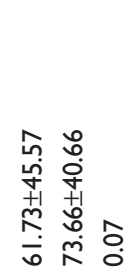 & 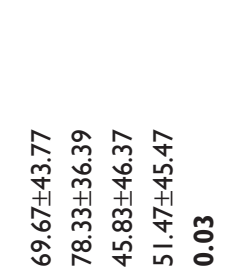 & 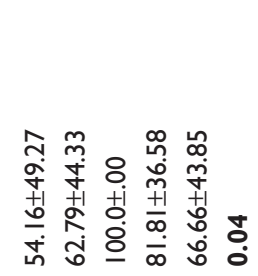 & 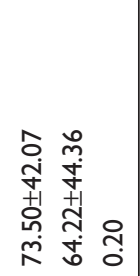 \\
\hline 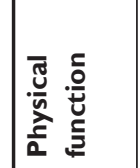 & 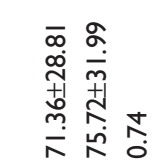 & 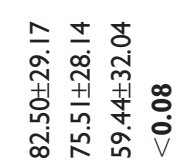 & 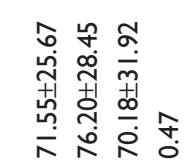 & 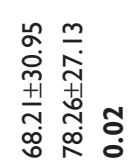 & 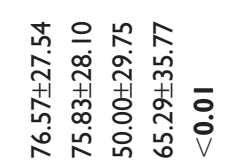 & 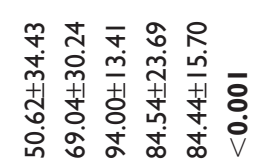 & 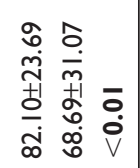 \\
\hline 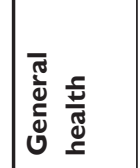 & 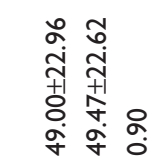 & 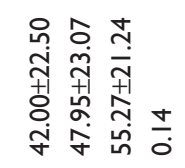 & 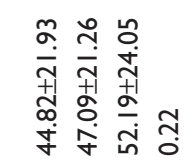 & 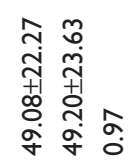 & 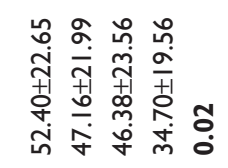 & 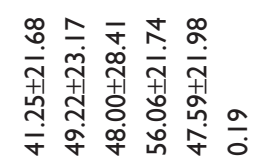 & 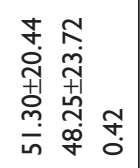 \\
\hline 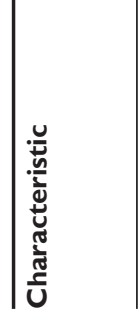 & 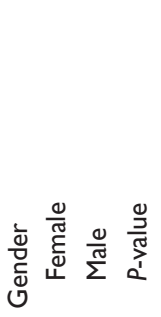 & 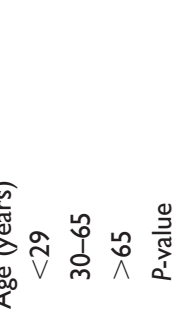 & 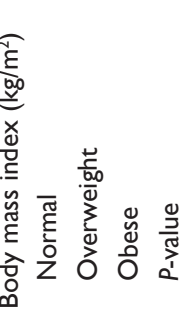 & 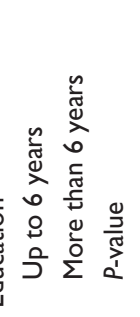 & 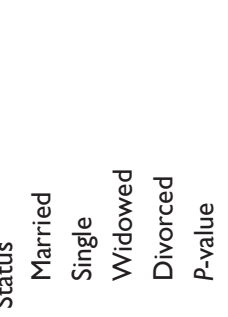 & 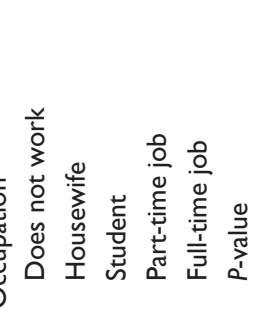 & 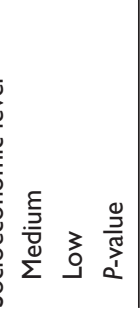 \\
\hline
\end{tabular}




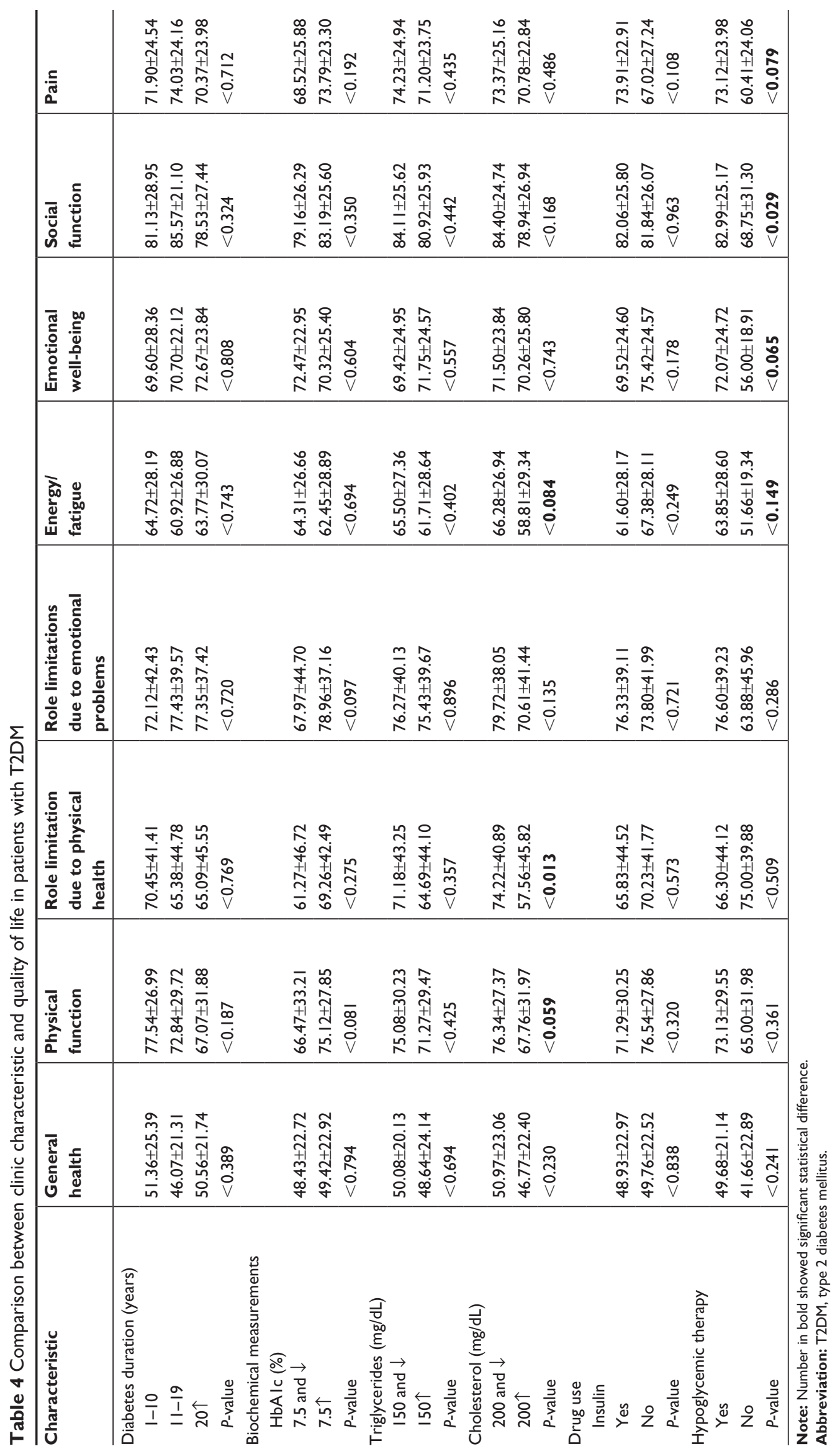


Table 5 Comparison of SF-36 dimensions among patients with T2DM with and without depression

\begin{tabular}{|c|c|c|c|c|}
\hline $\begin{array}{l}\text { SF-36 } \\
\text { measure }\end{array}$ & Domain and SF-36 dimensions & $\begin{array}{l}\text { Patients without } \\
\text { depressive symptoms } \\
(\text { CES-D }<\text { I6), } \\
\text { mean } \pm \text { SD }\end{array}$ & $\begin{array}{l}\text { Patients with } \\
\text { depressive symptoms } \\
(C E S-D \geq 16) \\
\text { mean } \pm \text { SD }\end{array}$ & $P$-value \\
\hline \multirow[t]{4}{*}{ Physical health } & Physical function & $74.78 \pm 28.85$ & $63.18 \pm 31.81$ & 0.04 \\
\hline & Role limitation due to physical health & $73.03 \pm 41.12$ & $40.90 \pm 45.85$ & $<0.001$ \\
\hline & Pain & $74.62 \pm 22.84$ & $62.12 \pm 27.09$ & $<0.01$ \\
\hline & General health & $52.50 \pm 22.43$ & $34.84 \pm 18.68$ & $<0.001$ \\
\hline \multirow[t]{4}{*}{ Mental health } & Energy/fatigue & $68.92 \pm 25.52$ & $37.87 \pm 25.24$ & $<0.001$ \\
\hline & Social function & $86.87 \pm 20.73$ & $61.36 \pm 34.14$ & $<0.001$ \\
\hline & Emotional well-being & $77.62 \pm 19.86$ & $42.66 \pm 23.10$ & $<0.001$ \\
\hline & Role limitation due to emotional problems & $85.47 \pm 31.02$ & $34.34 \pm 46.01$ & $<0.001$ \\
\hline \multirow[t]{2}{*}{ Summary scores } & Physical component summary & $69.13 \pm 22.30$ & $52.09 \pm 25.60$ & $<0.001$ \\
\hline & Mental component summary & $78.14 \pm 19.36$ & $42.18 \pm 26.52$ & $<\mathbf{0 . 0 0 1}$ \\
\hline
\end{tabular}

Note: Numbers in bold showed significant statistical different.

Abbreviations: CES-D, Clinical Epidemiological Studies of Depression; SF-36, Short Form-36; T2DM, type 2 diabetes mellitus.

component summaries. ${ }^{32}$ Finally, we observed a positive effect of the use of insulin on the quality of life of these patients, which is supported by literature..$^{33}$ Nevertheless, more studies are necessary for a conclusive result.

\section{Limitations}

We recognized some limitations in our study. First, we did not have a control group. Second, the number of participants could be considered small. Third, the women were overrepresented, and this might introduce bias, as clinical depression could be significantly higher in females than in males. We expect that, in the future, other authors will use our findings and further investigate on larger samples.

\section{Conclusion}

In conclusion, our findings provide information about the consequences of having T2DM along with unrecognized and untreated depression. When depression is underrecognized, it becomes a clinical problem itself and a challenge to treat. Depression decreases the quality of life, impacting negatively on the self-management of patients with T2DM. We suggest that health providers inquire in detail about the patients' physical and mental state, as well as their selfmanagement, in order to ensure the best quality of life for these patients.

\section{Acknowledgment}

Data collection of participants was performed with the support through a grant from Universidad Juárez Autónoma de Tabasco (UJAT-IB-2105-05).

\section{Disclosure}

The authors report no conflicts of interest in this work.

\section{References}

1. Gao HX, Regier EE, Close KL. International Diabetes Federation World Diabetes Congress 2015. J Diabetes. 2016;8(3):300-302.

2. International Diabetes Federation. IDF Diabetes Atlas. Brussels, Belgium: International Diabetes Federation; 2015.

3. Mcknight-Menci H, Sababu S, Kelly SD. The care of children and adolescents with type 2 diabetes. J Pediatr Nurs. 2005;20(2):96-.

4. Altinok A, Marakoglu K, Kargin NC. Evaluation of quality of life and depression levels in individuals with Type 2 diabetes. J Family Med Prim Care. 2016;5(2):302-308.

5. Tchicaya A, Lorentz N, Demarest S, Beissel J, Wagner DR. Relationship between self-reported weight change, educational status, and healthrelated quality of life in patients with diabetes in Luxembourg. Health Qual Life Outcomes. 2015;13:149.

6. Anaforoğlu I, Ramazanoğulları I, Algün E, Kutanis R. Depression, anxiety and quality of life of family caregivers of patients with type 2 diabetes. Med Princ Pract. 2012;21(4):360-365.

7. Egede LE, Hernández-Tejada MA. Effect of comorbid depression on quality of life in adults with Type 2 diabetes. Expert Rev Pharmacoecon Outcomes Res. 2013;13(1):83-91.

8. Bahety P, Agarwal G, Khandelwal D, et al. Occurrence and predictors of depression and poor quality of life among patients with Type-2 diabetes: A Northern India perspective. Indian Journal of Endocrinology and Metabolism. 2017;21(4):564.

9. Lustman PJ, Griffith LS, Clouse RE. Depression in adults with diabetes. Results of 5-yr follow-up study. Diabetes Care. 1988;11(8):605-612.

10. Musselman DL, Betan E, Larsen H, Phillips LS. Relationship of depression to diabetes types 1 and 2: epidemiology, biology, and treatment. Biol Psychiatry. 2003;54(3):317-329.

11. Zhang P, Lou P, Chang G, et al. Combined effects of sleep quality and depression on quality of life in patients with type 2 diabetes. $B M C$ Fam Pract. 2016;17:40.

12. Mishra SR, Sharma A, Bhandari PM, Bhochhibhoya S, Thapa K. Depression and Health-Related Quality of Life among Patients with Type 2 Diabetes Mellitus: A Cross-Sectional Study in Nepal. PLoS One. 2015;10(11):e0141385.

13. Ali S, Stone M, Skinner TC, Robertson N, Davies M, Khunti K. The association between depression and health-related quality of life in people with type 2 diabetes: a systematic literature review. Diabetes Metab Res Rev. 2010;26(2):75-89.

14. Caballero C, Hernández B, Moreno H, et al. Obesidad, actividad e inactividad física en adolescentes de Morelos, México: un estudio longitudinal. Archivos Latinoamericanos de nutrición. 2007;57(3):231. 
15. de Salubridad General C. Guía de práctica clínica. Prevención, diagnóstico y tratamiento de la enfermedad renal crónica temprana. México: Secretaría de Salud Recuperado de; 2009. Available from: http://www. cenetec.salud.gob.mx/descargas/gpc/CatalogoMaestro/335_IMSS_09_ Enfermedad_Renal_Cronica_Temprana/EyR_IMSS_335_09.pdf. Accessed January 31, 2018.

16. de la Federación DO. [NORMA Official Mexican NOM-015-SSA22010, For the prevention, treatment and control of diabetes mellitus] NORMA Oficial Mexicana NOM-015-SSA2-2010, Para la prevención, tratamiento y control de la diabetes mellitus. Recuperado de; 2010. Available from: http://dof.gob.mx/nota_detalle.php?codigo=5168074 $\&$ fecha $=23 / 11 / 2010$. Accessed Januarury 31, 2018.

17. Reyes-Ortega M, Soto-Hernández AL, Milla-Kegel JG, et al. Actualización de la Escala de Depresión del Centro de Estudios Epidemiológicos (CES-D). Estudio piloto en una muestra geriátrica mexicana. Salud Ment. 2003;26(1):59-68.

18. Pichot P, Aliño JJL-I, Miyar MV. DSM-IV: Manual Diagnóstico y Estadístico de los Trastornos Mentales. Editorial Masson. Mexico: SA Primera Edición. 1995.

19. Lopez CA. Manual Diagnóstico y Estadístico de los Trastornos Mentales: DSM-5. Madrid: Editorial Medica Panamericana; 2014.

20. Martinez-Hernandez L, Segura-Mendez N, Antonio-Ocampo A, TorresSalazar A, Murillo-Gomez E. Validation of the SF-36 questionnaire in adults with asthma and allergic rhinitis in Mexican population. Revista Medica del Instituto Mexicano del Seguro Social. 2009; 48(5):531-534.

21. Bahety P, Agarwal G, Khandelwal D, et al. Occurrence and Predictors of Depression and Poor Quality of Life among Patients with Type-2 Diabetes: A Northern India Perspective. Indian J Endocrinol Metab. 2017;21(4):564-569.

22. Goldney RD, Phillips PJ, Fisher LJ, Diabetes WDH. Diabetes, depression, and quality of life. Diabetes Care. 2004;27(5):1066-1070.

23. Altınok A, Marakoğlu K, Kargın NÇ. Evaluation of quality of life and depression levels in individuals with Type 2 diabetes. J Family Med Prim Care. 2016;5(2):302.
24. Bădescu SV, Tătaru C, Kobylinska L, et al. The association between Diabetes mellitus and Depression. J Med Life. 2016;9(2):120.

25. Rustad JK, Musselman DL, Nemeroff CB. The relationship of depression and diabetes: pathophysiological and treatment implications. Psychoneuroendocrinology. 2011;36(9):1276-1286.

26. Mcmartin SE, Jacka FN, Colman I. The association between fruit and vegetable consumption and mental health disorders: evidence from five waves of a national survey of Canadians. Prev Med. 2013;56(3-4): 225-230.

27. Weyerer S. Physical Inactivity and Depression in the Community. Int J Sports Med. 1992;13(06):492-496.

28. Li J, Sun X, Yu Y. The prevalence of impaired glucose regulation in psychiatric patients with sleep disorders and its relationship with altered hypothalamopituitary-adrenal and hypothalamopituitary-thyroid axis activity. Sleep Med. 2013;14(7):662-667.

29. Dantzer R, O’Connor JC, Freund GG, Johnson RW, Kelley KW. From inflammation to sickness and depression: when the immune system subjugates the brain. Nat Rev Neurosci. 2008;9(1):46-56.

30. Akinci F, Yildirim A, Gözü H, Sargin H, Orbay E, Sargin M. Assessment of health-related quality of life (HRQoL) of patients with type 2 diabetes in Turkey. Diabetes Res Clin Pract. 2008;79(1):117-123.

31. Jacobson AM, de Groot M, Samson JA. The evaluation of two measures of quality of life in patients with type I and type II diabetes. Diabetes Care. 1994;17(4):267-274.

32. Dogan H, Harman E, Kocoglu H, Sargin G. Can metabolic control variables of diabetic patients predict their quality of life? J Am Soc Hypertens. 2016;10(1):81-88.

33. Fal AM, Jankowska B, Uchmanowicz I, Sen M, Panaszek B, Polanski J. Type 2 diabetes quality of life patients treated with insulin and oral hypoglycemic medication. Acta Diabetol. 2011;48(3): $237-242$.
Neuropsychiatric Disease and Treatment

\section{Publish your work in this journal}

Neuropsychiatric Disease and Treatment is an international, peerreviewed journal of clinical therapeutics and pharmacology focusing on concise rapid reporting of clinical or pre-clinical studies on a range of neuropsychiatric and neurological disorders. This journal is indexed on PubMed Central, the 'PsycINFO' database and CAS,

\section{Dovepress}

and is the official journal of The International Neuropsychiatric Association (INA). The manuscript management system is completely online and includes a very quick and fair peer-review system, which is all easy to use. Visit http://www.dovepress.com/testimonials.php to read real quotes from published authors. 